\title{
THE HUMANISM IN THE PRACTICE AND FORMATION OF NURSING: A TRANSFORMING PROCESS
}

The nursing profession has emerged in Latin American countries as a social service that later turned into a profession*. It was in the modern age or well known as the post-Nightengalean era, whose initial period is started in the twentieth century, when through various educational processes, changed this occupational vision into the professional approach. The particularities that have characterized the origin and development of Nursing in more than a century, have a close bond with the historical, cultural, social, economic and political conditions that accompanied its formation process.

In this context, it is important to consider that the training of nursing personnel, at least for 70-80 years in the last century, was held before a French vocational educational model, also called the Napoleonic style, favoring the acquisition of knowledge and mainly skills that meet the care needs of disease in the hospital areas. On the other hand, the assistance has also been characterized by three types of knowledge: empirical-practical, theoretical-practical and theoretical-prátical. ${ }^{1}$

In both situations, the humane care has been present mainly referred to various acts of religiousness, charity, helping others, concern for others, participation, commitment and motivation, traits that are usually attributed to the vocation. This is related to the acceptance of appropriate norms and standards, the idea of identification with their peers and the community. The notion of service of the nursing staff has gone changing, especially if we take into consideration the philosophy inherited from the nineteenth century, when the provision of care was associated with charitable purposes and self-sacrifice. Here the nursing staff tried to save his own soul by saving the soul of their patients through body care actions that integrates the Catholic mysticism of the charitable care to the poor population and/or to the disable people, with the Protestant ethic of the asceticism. In this sense, the mystique of the profession is generally supported by a code of ethics, which is one of the most important elements of the profession and becomes as a professional self-control mechanism.

For over a century, Latin American nurses have passed through different paths in searching a position in the professional, technical and social context. Along the way, they have increased the theoretical and disciplinary knowledge by obtaining academic degrees; by developing significant research, by intensifying the use of informational technology and by expanding the accreditation process and the assessment of knowledge, skills, processes and outcomes, individual and collective, as a product of the neoliberal economic system, that favors a closer approximation to the national state and promotes the private initiative. It is evident that with this, the career has obtained exponential achievements in the advancement of the profession, however, it seems that the essence of Nursing has been postponed, that means the care with humanism.

There are at least two major evidence that justify this statement. First, the increasingly frequent opinion of the patients, family and society with regards the nursing professional services, which manifest a mechanistic, depersonalized and absence of personal and professional empathy in the treatment of a person who is facing a health condition. Then the concern of experts in the profession, they are turning their look to the ethical and aesthetic aspects that are essential in the comprehensive care of a person who requires a therapeutic care and holistic care. This professional recommend to perform functions and actions that promote and position the nursing profession, giving visibility and impact on the contribution, commitment and civic responsibility, of the nursing staff.

Currently the social and professional conditions may be appropriate to reflect on the Being, Knowing and Doing in Nursing. In the $21^{\text {st }}$ century we seem to have built an individual identity, but I wonder

* We understand as profession to the process that establishes some criteria for the training and performance of an occupation or profession, whose primary purpose is to increase the status and social prestige, not only of the profession but also of those who practice it. 
where are our roots, our collective identity, our citizenship and our social commitment? If these questions seem to be superfluous, it would be appropriate to reflect on how we ambitious our professional identity? The educational and assistencial scenarios are tinted by the individualism and the competition that hurts the identity in a collective way.

What this is generating is a crisis which could be overcome through the transition from a competitive globalization to collaborative globalization. Within this approach, it is necessary to transform the education and professional nursing practice, which core and essence is the humanism, which does not exclude the epistemological, technical, empirical, scientific, ethical, aesthetic and technological knowledge.

Humanism in Nursing, can be simply understood as the act of understanding and treating the human being as a person, in other words, "to treat the other as you want to be treated". From this perspective, we must remember that when we decide to be nurses, we thought to help, care and support others. So humanism is inherent to our nature and in this sense our career is born by the person we are. This reflection does not intend to make a broad theoretical argument about humanism, but seeks to return to the everyday care and to the being in the world and growing as a professional with a sense of attention and euphemism of "thinking with the heart and feeling with the intellect".

It is necessary to start a personal revolution, to unlearn to relearn, to recognize as the greater the knowledge, the greater the humanism; bear in mind that the important thing for patient is to have an affective environment, being surrounded by people who love him, to have the freedom that allows him to make decisions; to be comfortable in a physical and mental way and to find himself in a stimulating environment for the senses. Jean Watson states that " The environment is like a magnetic field of hope when the nurse enters the room". $2: 7$

It is necessary to take the appropriate time to give care with contact and communication, to listen to the questions, to always observe the non-verbal communication, to have honest communication; to provide positive techniques trough a smile, through eye contact, by touching their arms, shoulders or hands, to actively explain and listen and/or to keep silence. The communication must be with empathy, respect, authenticity, in a word, with humanity; we must listen to each other with the soul, heart and body. We must love our profession which involves love and attitude for the service, to be empowered, to work as a group with the health team and to become into examples for the other. In this encounter with ourselves, with the profession and with the society, we should develop and promote successful evidence that allows permanent links between teaching and assistance.

There is always time to create and recreate a visible, empowered, cooperatively and with a high sense of humanistic Nursing. This transforming, critical and not catatonic hope approach, will help to build a better Nursing.

\section{REFERENCES}

1. Cárdenas-Becerril L. La profesionalización de Enfermería en México: un análisis desde la sociología de las profesiones. Barcelona (ES): Pomares; 2005, p. 120-48.

2. Watson J. Nursing: the philosophy and science of caring. Boulder (US): University Press of Colorado; 2008.

\section{Lucila Cárdenas Berrerril}

Nurse. Ph.D. in Education. Professor and Researcher at the Faculty of Nursing and Midwifery at the Autonomous University of the State of Mexico. Member of the National System of Researchers Level 1 and of the National Council of Science and Technology of Mexico. Coordinator of the region of Mexico and Caribbean of the Ibero-American Network of Nursing Education Research 